\title{
ANALISIS PENGGUNAAN JŌKEN HYŌGEN PADA NOVEL "SENSEI HA MAHOUKKAI?" KARYA NAKAMURA KOUZOU (Kajian: Struktur dan Makna)
}

\section{Rindi Andriani ${ }^{1}$, Damai Yani, ${ }^{2}$}

${ }^{1}$ (Mahasiswa Pendidikan Bahasa Jepang, Bahasa dan Sastra Inggris, Fakultas Bahasa dan Seni, Universitas Negeri Padang), Jl. Prof. Dr. Hamka Air Tawar, Padang 25131

2 (Dosen Pendidikan Bahasa Jepang, Bahasa dan Sastra Inggris, Fakultas Bahasa dan Seni, Universitas Negeri Padang), Jl. Prof. Dr. Hamka Air Tawar, Padang 25131 Email Penulis : rindi22andriani@gmail.com

\section{Sejarah Artikel \\ Submit : 2020-08-18 \\ Diterima : 2020-09-29}

Diterbitkan :2020-12-11

\section{Kata Kunci:}

jyouken hyougen, struktur dan makna, Nakamura Kouzo.

\begin{abstract}
This research is a research on the analysis of the structure and meaning of the jyouken hyougen in the novel sensei ha mahoukkai by Nakamura Kouzou. This study aims to determine the types of presupposition expressions contained in Nakamura Kouzo's Sensei Ha Mahoukkai novel, as well as the structure and meaning of these sentences. Data analysis was carried out using descriptive qualitative methods with semantic and sintaksis design based on the theoretical collaboration of Dedi Sutedi, Masuoka and Sunagawa.The results of this study are, there are 35 data of presupposition expres sions. among them, 16 data are the jyouken hyougen of to, 12 data are the jyouken hyougen of tara, and 7 data are the jyouken hyougen of ba. Then, based on the structure, these data generally experience attachment to clauses (S1) and main sentences (S2) in the form of dictionary form verbs, negative verbs, nouns, and adjectives. The most common meanings are, namely, the meaning in the form of cause and effect, habit, the meaning of stating a general event, an event of a natural nature, and how the machine works.
\end{abstract}

\section{PENDAHULUAN}

Pada era globalisasi, kebutuhan terhadap kemampuan berbahasa sangat tinggi, terutama bahasa asing. Ada banyak pembelajaran bahasa asing di Indonesia, salah satunya bahasa Jepang. Bahasa Jepang merupakan salah satu bahasa asing yang jumlah pembelajarnya banyak di Indonesia. Berdasarkan data survei The Japan Foundation tahun 2018 tercatat bahwa Indonesia adalah negara terbanyak pembelajar bahasa Jepang kedua setelah China.

\footnotetext{
${ }^{1}$ Mahasiswa Prodi Pendidikan Bahasa Jepang FBS UNP lulus pada tanggal 20 Agustus 2020
} 
2 Dosen Prodi Pendidikan Bahasa Jepang FBS UNP

Hal ini menunjukkan bahwa bahasa Jepang di Indonesia banyak diminati. Di antara banyak peminat tersebut, tidak sedikit yang mengalami kesulitan dalam memahami dan mengaplikasikan bahasa Jepang dalam kehidupan sehari-hari.

Dalam bahasa Jepang maupun bahasa Indonesia, sama-sama terdapat ungkapan pengandaian atau persyaratan, namun memiliki makna yang berbeda. Iori, dkk (dalam Indraswari (2017:132)) mengungkapkan bahwa pada sistem gramatikal bahasa Jepang dan bahasa Indonesia, sama-sama dikenal jenis kalimat luas bertingkat yang menyatakan syarat; dalam bahasa Jepang dinyatakan oleh penggunaan to, tara, ba, nara. Sedangkan, dalam bahasa Indonesia dinyatakan oleh penggunaan kalau, jika, bila, apabila. (Chaer, 2009: 98-99).

Ungkapan pengandaian dalam bahasa Jepang disebut Jōken Hyōgen. Menurut Tanaka (dalam Hayashi (2005:4)) dituliskan bahwa ungkapan pengandaian bahasa Jepang adalah dua uraian peristiwa berbeda dan saling berhubungan, yang menjadi suatu kesatuan dalam kalimat yang digambarkan secara umum. Pendapat serupa disampaikan oleh Sutedi (2016:23) yaitu pengandaian dalam bahasa Jepang diekspresikan dengan menggunakan empat bentuk verba, yaitu verba bentuk kamus ditambah partikel to $(v$-to), verba bentuk $b a(v-b a)$, verba bentuk lampau (bentuk $t a)$ ditambah ra (v-tara), dan verba bentuk biasa ditambah nara (v-nara), yang masingmasing memiliki ciri tersendiri. Persamaan keempat bentuk pengandaian tersebut berpadanan dengan kata jika atau kalau dalam bahasa Indonesia.

Dari pendapat di atas dapat di simpulkan bahwa ungkapan pengandaian dalam bahasa Indonesia adalah jenis kalimat luas bertingkat yang menyatakan syarat; yang dinyatakan dengan penggunaan kalau, jika, bila, apabila. Sedangkan jōken hyōgen adalah uraian dua peristiwa yang berbeda di ungkapkan menggunakan konjungsi to, ba, tara, dan nara.

Menurut Sutedi (2016:24) jouken hyougen merupakan

"salah satu materi tata bahasa (bunpou) yang cukup sulit bagi pembelajar bahasa Jepang sebagai bahasa asing, termasuk pembelajar bahasa Jepang di Indonesia. Materi pengandaian dalam bahasa Jepang cukup banyak dan kompleks, sehingga tidak mungkin untuk disampaikan dalam satu pelajaran pada level dasar saja. Akan tetapi, keempat bentuk pengandaian tersebut sudah muncul pada buku ajar tingkat dasar dalam satu pelajaran secara keseluruhan. Tentunya hal ini akan memberatkan pembelajar mengingat cakupan dan kedalaman materinya cukup banyak, dan ada bagian yang tidak mungkin dijelaskan pada pembelajar tingkat dasar. Ungkapan jōken hyōgen memiliki aturan tersendiri dalam pemakaiannya. seperti yang tampak pada contoh berikut:

(1) 新しいアパートに引つ越すと、住所を教えてください。

Atarashii apaato ni hikkosu to (S1), juusho wo oshiete kudasai (S2).

'Kalau pindah ke apartemen baru, tolong beri tahu alamatnya!'

(2) 新しいアパートに引つ越せば、住所を教えてください

Atarashii apaato ni hikkoseba (S1), juusho wo oshiete kudasai (S2).

'Kalau pindah ke apartemen baru, tolong beri tahu alamatnya!'

(3) 新しいアパートに引つ越したら、住所を教えてください 
Atarashii apaato ni hikkoshitara (S1), juusho wo oshiete kudasai (S2). 'Kalau pindah ke apartemen baru, tolong beri tahu alamatnya!'

(4) 新しいアパートに引つ越すなら、住所を教えてください Atarashii apaato ni hikkosu nara (S1), juusho wo oshiete kudasai (S2). 'Kalau pindah ke apartemen baru, tolong beri tahu alamatnya!'

Pada contoh di atas pengenadaian bentuk $v$-to dan bentuk $v$-ba tidak berterima, sedangkan bentuk v-tara dan v-nara kedua-duanya berterima. Kandungan pernyataan dalam S1 (pindah ke apartemen baru) dan S2 (menelepon) kedua-duanya merupakan perbuatan yang dilakukan oleh subjek yang sama. Kemudian jika diamati bentuk predikat dalam S2-nya merupakan bentuk perintah, sehingga bisa disimpulkan bahwa $v$-to dan $v$-ba tidak bisa digunakan dalam pengandaian yang diikuti oleh S2 yang berupa perintah dan sejenisnya. Akan tetapi pada contoh berikut $v$-ba bisa digunakan.

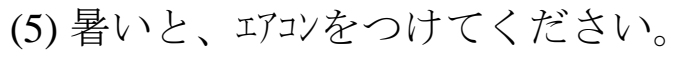
Atsui to (S1), eakon wo tsukete kudasai (S2).

Kalau (merasa) panas, nyalakan saja AC-nya!'

(6) 暑ければ、エアコンをつけてください。

Atsukereba (S1), eakon wo tsukete kudasai (S2).

'Kalau (merasa) panas, nyalakan saja AC-nya!'

(7) 暑かったら、エアコンをつけてください。

Atsukattara (S1), eakon wo tsukete kudasai (S2).

'Kalau (merasa) panas, nyalakan saja AC-nya!'

(8) 暑いなら、エアコンをつけてください。

Atsui nara (S1), eakon wo tsukete kudasai (S2).

'Kalau (merasa) panas, nyalakan saja AC-nya!'

Pada contoh di atas, pernyataan dalam S1 (merasa panas) berupa suatu keadaan, tetapi pernyataan dalam S2 (menyatakan AC) berupa suatu perbuatan yang disajikan dalam bentuk perintah. Bentuk $v$-ba pada contoh no (7) menjadi berterima karena S1-nya berupa suatu keadaan bukan perbuatan. Dengan demikian dapat disimpulkan bahwa $v$-ba bisa diikuti oleh S2 bentuk perintah dan sejenisnya, asalkan S1-nya berupa suatu keadaan.

(9) 今、出かけると、金を持っていきなさい。

Ima, dekakeruto(S1), kasa wo motte ikinasai(S2).

'Kalau mau keluar sekarang, pergilah dengan membawa payung!'

(10) 今、出かければ、傘を持っていきなさい。

Ima, dekakereba(S1), kasa wo motte ikinasai(S2).

'Kalau mau keluar sekarang, pergilah dengan membawa payung!'

(11) 今、出かけたら、傘を持っていきなさい。

Ima, dekaketara(S1), kasa wo motte ikinasai(S2).

'Kalau mau keluar sekarang, pergilah dengan membawa payung!'

(12) 今、出かけるなら、傘を持っていきなさい。 
Ima, dekakerunara(S1), kasa wo motte ikinasai(S2).

'Kalau mau keluar sekarang, pergilah dengan membawa payung!'

'Kalau mau keluar sekarang, pergilah dengan membawa payung!' Pada contoh di atas, kejadian S1 (keluar/bepergian) dan S2 (membawa payung) dilakukan secara bersamaan dan hanya dapat diekpresikan dengan bentuk vnara, sedangkan bentuk yang lainnya tidak bisa. Selain itu, fungsi v-nara pada konteks di atas dapat dianggap sebagai pengangkatan topik yang menjadi isi pembicaraan yang dikemukakan oleh lawan bicara pada kalimat sebelumnya yang tidak ditampilkan di atas. Oleh karena itu, dalam S1 hal tersebut dijadikan sebagai topik sebagai bahan pertimbangan untuk mengucapkan S2. Fungsi ini hanya dimiliki oleh v-nara". (Sutedi dan Wijayanti, 2016)

Novel "Sensei ha Mahoukkai?" adalah sebuah karya seorang penulis sastra anak-anak Jerman yang representatif di Jerman modern, yang terkenal di Jepang oleh mahakarya tersebut. Beliau adalah Frois Lar. Novel ini diterjemahkan oleh Nakamura Kouzou. Novel ini berkisah tentang para siswa dan seorang guru yang menggunakan sihir.

Dalam Novel tersebut penulis menemukan banyak penggunaan jōken hyōgen. Penelitian ini penulis lakukan agar pembelajar bahasa Jepang lebih memahami penggunaan Jōken Hyōgen. Kemudian, pada penelitian-penelitian sebelumnya di Universitas Negeri Padang, belum pernah dilakukan penelitian mengenai penggunaan Jōken Hyōgen, baik objek penelitiannya pada mahasiswa maupun pada karya sastra Jepang. Berdasarkan hal tersebut, penulis tertarik melakukan penelitian yang berjudul "Penggunaan Jōken Hyōgen pada Novel Sensei Ha Mahoukkai? (Kajian Struktur dan Makna)".

\section{METODE PENELITIAN}

Penelitian ini merupakan jenis penelitian kualitatif. Penelitian ini dikatakan penelitian kualitatif karena data yang digunakan berupa data deskriptif yang di ukur dengan data berupa kata-kata bentuk lisan maupun tulisan bukan berupa data berbentuk angka. Penelitian deskriptif mempelajari masalah masalah dalam masyarakat, serta tata cara yang berlaku dalam masyarakat serta situasi-situasi tertentu, termasuk tentang hubungan, kegiatan-kegiatan, sikap-sikap, pandanganpandangan, serta proses-proses yang sedang berlangsung yang mempengaruhi suatu fenomena. Data yang diperoleh dari penlitian ini adalah data kualitatif, yaitu jyouken hyougen dari novel Sensei Ha Mahoukkai?. Sedangkan sumber data untuk penelitian ini yaitu novel Sensei Ha Mahoukkai?.

Dalam penelitian kualitatif, yang menjadi instrumen atau alat penelitian adalah peneliti itu sendiri. Selain itu, alat bantu lainnya yang penulis gunakan dalam penelitian ini yaitu tabel inventaris data. Tabel ini berguna untuk mengumpulkan data, mengklasifikasi dan menganalisis data yang diperoleh berupa data yang berhubungan dengan jyouken hyougen yang terdapat dalam Novel Sensei Ha Mahoukkai?. Teknik pengumpulan data yang akan penulis gunakan yaitu teknik simak dan teknik catat. Teknik analisis data dalam penelitian ini adalah teknik analisis deskriptif. Guna analisis data yang penulis lakukan yaitu untuk menngetahui jenis, struktur, dan makna keempat konjungsi jyouken hyougen. 


\section{HASIL DAN PEMBAHASAN}

\section{Deskripsi Data}

Pada penelitian ini, penulis meneliti keempat jenis jyouken hyugen yang terdiri dari to, tara, ba dan nara yang terdapat dalam novel "Sensei Ha Mahoukkai" karya Nakamura Kouzou. Dari novel tersebut, penulis menemukan 35 kalimat yang merupakan jyouken hyougen, yang terdiri dari 16 jyouken hyougen to, 12 jyouken hyougen tara, 7 jyouken hyougen ba, 0 jyouken hyougen nara.

Tabel 1.

Deskripsi Data

\begin{tabular}{|l|l|l|l|l|}
\hline \multicolumn{4}{|l|}{ Jenis Jyouken Hyougen } & \multirow{2}{*}{ Jumlah } \\
\cline { 1 - 4 } To & Tara & Ba & Nara & \\
\hline 16 & 12 & 7 & 0 & 35 \\
\hline
\end{tabular}

\section{Pembahasan}

Berdasarkan hasil analisis data pada penelitian ini ditemukan 38 kalimat yang mengandung jyouken hyougen.

\section{Jyouken Hyougen To}

Penggunaan jenis konjungsi to dalam novel "Sensei Ha Mahoukkai?" Nakamura Kouzou terdapat 16 kalimat. Dari data tersebut jenis jyouken hyougen yang paling banyak ditemukan yaitu jyouken hyougen to. Berdasarkan data yang didapat, jyouken hyougen to lebih banyak digunakan dalam novel Sensei $\mathrm{Ha}$ Mahoukkai? dibandingkan dengan jyouken hyougen lainnya. Hal ini dikarenakan dari segi maknanya, bahwa jyouken hyougen to memiliki makna yang lebih nyata terhadap pengandaiannya, seperti makna tentang cara kerja mesin. Makna 'cara kerja mesin' merupakan suatu makna yang pasti akan ditemukan hasilnya. Contoh kalimat :

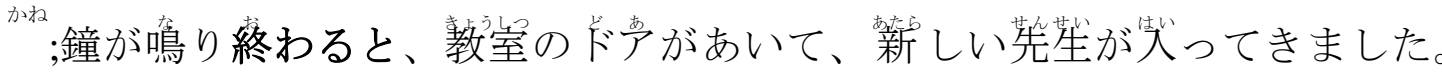 (SHM,1991:18)}

Kane ga nari oawaruto (S1), kyousitsu no doa ga aite, atarashii sensei ga haittekimashita (S2).

Jika bel selesai dibunyikan, pintu ruangan kelas akan terbuka, kemudian seorang guru baru, akan mssasuk.

Pada data diatas, terdapat pelekatan konjungsi to dengan anak kalimat (S1) yang terhubung dengan induk kalimat (S2). Berdasarkan strukturnya, pada kalimat di atas, konjungsi to melekat pada verba bentuk kamus (jishou-kei), yaitu (鳴り苳わる nari owaru) 'selesai berbunyi'. Kejadian pada kejadian S1 langsung disusul oleh S2, yaitu ketika bel telah selesai dibunyikan, maka pintu kelas akan langsung terbuka dan 
guru baru akan langsung masuk. Klausa anak kalimat (S1) 'Kane ga nari oawaruto' 'Jika bel selesai dibunyikan' dan induk kalimat 'atarashii sensei ga haittekimashita' 'pintu ruangan kelas akan terbuka, seorang guru baru, akan masuk' menggambarkan sebuah makna yaitu tentang pengoperasian suatu mesin. Apabila bel telah berbunyi, segera pintu kelas akan terbuka, kemudian guru baru, akan masuk ke kelas.

Pada kalimat jyouken hyougen to, konjungsi to melekat pada verba, nomina bentuk biasa bentuk positif dan negatif, bentuk sopan, non lampau, adjektiva $i$ dan adjektiva na. Konjungsi to tidak dapat melekat dengan induk kalimat yang menyatakan perintah, keinginan, permintaan dan ajakan, tapi konjungsi to dapat melekat dengan induk kalimat bentuk lampau dan menyatakan aktifitas berurutan.

Dalam analisis ini, terdapat 13 data yang melekat pada verba bentuk kamus (jishou-kei), kemudian 2 data melekat pada kata kerja bentu negatif (naikei), dan pada nomina (meishi) terdapat 1 data. Sedangkan, pada jyouken hyougen tara, konjungsi tara melekat pada verba, nomina bentuk positif maupun negatif, bentuk sopan, serta melekat pada adjetiva $i$ dan adjektiva na. Pada jyouken hyougen to, terdapat 6 data yang mengandung makna sebab akibat, 6 data mengandung makna kebiasaan, 3 data mengandung makna alami, dan 1 data mengandung makna tentang penggunaan suatu alat atau mesin.

\section{Jyouken Hyougen Tara}

Penggunaan konjungsi tara terdapat dalam novel "Sensei Ha Mahoukkai?" Nakamura Kouzou yaitu sebanyak 12 kalimat. Konjungsi tara dapat dihubungkan dengan induk kalimat yang menyatakan perintah, permintaan, keinginan, ajakan, induk kalimat bentuk lampau dan menyatakan aktifitas yang berurutan. Makna yang terkandung dalam jyouken hyougen tara diantaranya makna sebab akibat, makna untuk menyatakan kebiasaan, makna persyaratan. Contoh kalimat: みんながてんでんばらばらにさけんでいたら、ひとりの人間にわかるはずが ないじゃないか。(SHM,1991:22)

minna ga tenden barabara ni saken de itara (S1), hitori no ningen ni wakaru ha zuganai jyanaika (S2).

Jika semua orang saling mengacaukan, tidak mungkin seorang manusia akan memahaminya.

Pada data diatas, terdapat pelekatan konjungsi tara dengan klausa anak kalimat (S1) yang terhubung dengan klausa induk kalimat (S2). Berdasarkan strukturnya, konjungsi tara mengalami pelekatan pada klausa anak kalimat (S1), yaitu berupa verba bentu kamus (jishou-kei), (いう iru) 'ada'. Pada kalimat di atas, kejadian pada S2 disadari atau diketahui setelah S1 benar-benra telah terjadi. Ketika semua orang mengacaukan suasana, baru disadari bahwa seorangpun tidak akan memahaminya. Klausa anak kalimat (S1) yang melekat pada konjungsi tara, dan induk kalimat setelahnya mengandung makna yaitu sebab akibat. Hal ini di buktikan dengan induk kalimat yang terdapat setelah konjungsi tara mengandung makna akibat, yaitu 'hitori no ningen ni wakaru ha zuganai jyanaika' 'tidak mungkin seorang manusia akan memahaminya', yang merupakan akibat yang diterima karena perbuatan pada anak 
kalimatnya 'minna ga tenden barabara ni saken de itara' 'jika semua orang saling mengacaukan'. Oleh karena itu data diatas mengandung makna berupa sebab akibat.

. Pada penelitian ini, ditemukan 9 data melekat pada verba bentuk kamus (jishou-kei), 1 data mengalami pelekatan pada kata kerja bentuk negatif (naikei), 1 data mengalami pelekatan pada verba bentuk terlihat (mieru), dan 1 data mengalami pelekatan pada verba bentuk bisa (kanoukei). Pada analisis makna jyouken hyougen tara terdapat 12 kalimat yang mengandung makna pengandaian. Diantaranya, terdapat 4 data yang mengandung makna sebab akibat, 6 data mengandung makna untuk menyatakan kebiasaan, dan 2 data mengandung makna persyaratan.

\section{Jyouken Hyougen Ba}

Konjungsi $b a$ memiliki fungsi penggunaan yaitu; menyatakan suatu pengandaian atau perumpamaan, menjelaskan suatu kejadian yang umumnya terjadi. Dalam Novel "Sensei Ha Mahoukkai?" karya Nakamura Kouzou terdapat 7 data penggunaan jyouken hyougen ba. konjungsi ba dalam kalimat jyouken hyougen melekat pada konjugasi verba, adjektiva $i$, adjektiva $n a$, nomina bentuk positif dan negatif non lampau. Sedangkan konjungsi $b a$ tidak dapat melekat pada bentuk lampau dan sopan. Contoh kalimat:

これでパウルヒェンは、ぶきっちょでもなければ、ふとりすぎでもないとい

うことが、みんなにわかっただろう。(SHM,1991:40)

Kore de Paulchen ha, bukiccho demo nakereba (S1), futorisugidemonai to iu koto ga, minna ni wakatta darou (S2).

Jika itu bukan gertakan,orang-orang tahu bahwa paulchen tidak terlalu gemuk.

Pada data diatas, terdapat pelekatan konjungsi $b a$ dengan klausa anak kalimat (S1) yang menghubungkan kalusa induk kalimat (S2). Berdasarkan strukturnya, pada kalimat data ini, konjungsi $b a$ melekat dengan klausa anak kalimat (S1) berupa penanda bentuk negatif, yaitu (ない nai) 'tidak'. Klausa anak kalimat 'Kore de Paulchen ha, bukiccho demo nakereba' 'jika itu bukan gertakan', dan induk kalimat 'futorisugidemonai to iu koto ga, minna ni wakatta darou' 'orang-orang tahu bahwa paulchen tidak terlalu gemuk', menjelaskan bahwa Paulchen hanya menggertak orang lain supaya orang lain mengakui dirinya kurus atau tidak terlalu gemuk. Hal ini menunjukkan suatu kejadian yang umum terjadi, yaitu ketika Paulchen menggertak lawan bicaranya.

Pada analisis ini, ditemukan 6 data yang mengalami pelekatan pada verba bentuk kamus (jishoukei), dan 1 data mengalami pelekatan pada verba bentuk menyatakan keinginan (tai). Pada analisis makna kalimat jyouken hyougen ba terdapat 2 data yang mengandung makna ketergantungan sebab akibat, 3 data mengandung makna untuk memperjelas suatu kejadian yang umum terjadi, 1 data mengandung makna kebiasaan, dan 1 data mengandung makna perumpamaan.

Berdasarkan data yang didapat, jyouken hyougen to lebih banyak digunakan dalam novel Sensei Ha Mahoukkai? dibandingkan dengan jyouken hyougen lainnya. 
Hal ini dikarenakan dari segi maknanya, bahwa jyouken hyougen to memiliki makna yang lebih nyata terhadap pengandaiannya, seperti makna tentang cara kerja mesin. Makna "cara kerja mesin"e merupakan suatu makna yang pasti akan ditemukan hasilnya. Sedangkan, jyouken hyougen nara tidak terdapat dalam novel ini. Berdasarkan strukturnya, konjungsi nara umumnya melekat pada nomina (meishi), adjektiva $i$ ( $i$ keiyoushi), adjektiva na (na keiyoushi), sedangkan dalam novel Sensei Ha Mahoukkai? kalimat jyouken hyoygen yang paling banyak mengalami pelekatan pada verba bentuk kamus (jishou-kei).

Jika dilihat kembali pada penelitian relevan, yaitu penelitian yang dilakukan oleh Setyawan (2014) yang berjudul "Analisis Konjungsi To, Ba dan Tara pada cerpen Kumo no Ito karya Akutagawa, Hitofusa no Budou karya Arishima" ditemukan beberapa persamaan dan perbedaan terhadap hasil penelitian. Persamaanya dengan hasil penelitian yang penulis lakukan yaitu, sama-sama membahas tentang konjungsi to, tara, dan ba dalam kalimat jyouken hyougen. Sedangkan, yang menjadi pembeda yaitu kajian penelitian yang dilakukan dan cara menganalisis struktur dan makna kalimat jyouken hyougen yang ditemukan.

\section{KESIMPULAN}

Jenis jyouken hyougen yang ditemukan dalam penelitian ini yaitu jyouken hyougen to, jyouken hyougen tara, dan jyouken hyougen ba. Kalimat yang mengandung jyouken hyougen berjumlah 35 kalimat, yang terbagi menjadi 16 jenis jyouken hyougen to, 12 termasuk jenis jyouken hyougen tara, kemudian terdapat 7 kalimat berjenis jyouken hyougen ba. Pada novel "Sensei Ha Mahoukkai?" jyouken hyougen yang paling banyak ditemukan yaitu penggunaan jyouken hyougen to.

Pada kalimat jyouken hyougen to, konjungsi to melekat pada verba, nomina bentuk biasa bentuk positif dan negatif, bentuk sopan, non lampau, adjektiva $i$ dan adjektiva $n a$. Dalam analisis ini, terdapat 13 data yang melekat pada verba bentuk kamus (jishou-kei), kemudian 2 data melekat pada kata kerja bentu negatif (naikei), dan pada nomina (meishi) terdapat 1 data. Sedangkan, pada jyouken hyougen tara, konjungsi tara melekat pada verba, nomina bentuk positif maupun negatif, bentuk sopan, serta melekat pada adjetiva $i$ dan adjektiva $n a$. Sedangkan, konjungsi tara dapat dihubungkan dengan induk kalimat yang menyatakan perintah, permintaan, keinginan, ajakan, induk kalimat bentuk lampau dan menyatakan aktifitas yang berurutan Pada penelitian ini, ditemukan 9 data melekat pada verba bentu kamus (jishou-kei), 1 data mengalami pelekatan pada kata kerja bentuk negatif (naikei), 1 data mengalami pelekatan pada verba bentuk terlihat (mieru), dan 1 data mengalami pelekatan pada verba bentuk bisa (kanoukei). Sementara itu konjungsi ba Sementara itu konjungsi ba melekat pada konjugasi verba, adjektiva $i$, adjektiva $n a$, nomina bentuk positif dan negatif non lampau. Pada analisis ini, ditemukan 6 data yang mengalami pelekatan pada verba bentuk kamus (jishoukei), dan 1 data mengalami pelekatan pada verba bentuk menyatakan keinginan (tai).

Dari analisis data jyouken hyougen di atas, terdapat analisis makna jyouken hyougen to, jyouken hyougen tara, jyouken hyougen ba. Pada jyouken hyougen 
to, terdapat 6 data yang mengandung makna sebab akibat, 6 data mengandung makna kebiasaan, 3 data mengandung makna alami, dan 1 data mengandung makna tentang penggunaan suatu alat atau mesin. Kemudian pada analisis makna jyouken hyougen tara terdapat 12 kalimat yang mengandung makna pengandaian. Diantaranya, terdapat 4 data yang mengandung makna sebab akibat, 6 data mengandung makna untuk menyatakan kebiasaan, dan 2 data mengandung makna persyaratan. Sedangkan pada kalimat jyouken hyougen ba terdapat 2 data yang mengandung makna ketergantungan sebab akibat, 3 data mengandung makna untuk memperjelas suatu kejadian yang umum terjadi, 1 data mengandung makna kebiasaan, dan 1 data mengandung makna perumpamaan.

\section{REFERENSI}

Azizah. Suci Siti. 2008. Analisis Konstrastif Ungkapan Pengandaian Bahasa Jepang dan Bahasa Indonesia. Skripsi. Bandung: UPI.

Bldg, Kojimachi Trusty dkk. 2012. Minna No Nihongo I. Corporation 3A: Japan. . 2013. Minna No Nihongo II. Corporation 3A: Japan.

Djiwandono, Soenardi. 2011. Tes Bahasa Pegangan bagi Pengajar Bahasa. PT Indeks: Jakarta.

Fadilah, Fani Asriani, dan Yulia, Nova.2019. Analisis Bahasa Hormat (Keigo) Pada Surat Formal Dalam Buku Shakaijinyoo No Nihongo Karya Nalti Noviant. Jurnal Omiyage. Vol. 2, No.3.

Fatmasari, Desi. 2015. Analisis Kesalahan Penggunaan Ungkapan Pengandaian ( To), ( Ba), ( Tara), Dan ( Nara) Pada Mahasiswa Prodi Pendidikan Bahasa Jepang Unnes. Skripsi. Semarang: UNNES.

Hayashi, Tomohiro. 2005. Jōken hyōgen - To, Ba, Tara, Nara. Diambil dari: http://www.fjweb.fju.edu.tw/fbj/research/report/94_1/94-1zyouken.pdf Januari 2020)

Indihadi, D. 2012. Analisis Kesalahan Berbahasa.[Online]. Dikutip dari file. upi.edu/Direktori/DUAL.../10_BBM_8.pdf.

Indraswari, Islami Thamita. 2017. "Analisis Kontrastif Kalau dalam Bahasa Indonesia dengan To, Ba, Tara dalam Bahasa Jepang”. Journal of Japanese Language Education \& Linguistics, Vol. 1 No. 1.

Parera, Jos Daniel. 1997. Linguistik Edukasional: Metode Pembelajaran Bahasa, Analisis, Kontrastif Antarbahasa, Analisis Kesalalhan Bahasa. Jakarta: Erlangga. 
Putri, Ikhlas, Fitrawati, dan Yani, Damai. 2018. Hubungan Kebiasaan Menonton Anime Dengan Analisis Kesalahan Penggunaan Josuushimahasiswa Tahun Masuk 2017 Program Studi Pendidikan Bahasa Jepang Universitas Negeri Padang. Jurnal Omiyage. Vol. 1, No. 2.

Rohadi. 2006. Bentuk Ungkapan dari Kata Sifat dan Kata Kerja. Jakarta: Kesaint Blanc.

Sari, Nia Novita. 2015. Analisis Kesalahan Pemakaian Joukenbun To, Tara, Ba, dan Nara Pada Mahasiswa Tingkat Ii Tahun Akademik 2014/2015 Departemen Pendidikan Bahasa Jepang Fakultas Pendidikan Bahasa Dan Sastra Universitas Pendidikan Indonesia. Skripsi. Bandung: UPI.

Setyawan, Tri Imam. 2014. Analisis Makna Konjungsi To, Ba, Tara Dalam Cerpen Kumo No Ito Karya Akutagawa Dan Hitofusa No Budou Karya Arishima. Skripsi. Semarang: UNDIP

Sugiyono. 2017. Metode Penelitian Pendidikan ( Pendekatan Kuantitatif, Kulaitatif, dan $R \& D)$. Bandung: Alfabeta.

Sutedi, Dedi. 2011. Penelitian Pendidikan Bahasa Jepang (Panduan Bagi Guru Dan Calon Guru Dalam Meneliti Bhsa Jepang Dan Pengajarannya. Bandung: Humaniora dan UPI Press.

Sutedi, Dedi \& Widianti, Susi. 2016. “Kalimat Pengandaian Bahasa Jepang: Kajian Sintaktis Dan Semantis”. Jurnal Pendidikan Bahasa dan Sastra, Vol. 16, No. 1.

Tarigan Henry Guntur. Dkk. 1996. Analisis kesalahan berbahasa. Jakarta: Department Pendidikan Kebudayaan.

Tarjo. 2019. Metode penelitian. Yogyakarta: Deepublish.

Untoro, Joko dan Tim Guru Indonesia. 2010. Buku Pintar Pelajaran SMA. Jakarta: Wahyumedia.

Zaim, M. 2014. Metode Penelitian Bahasa. Padang: FBS UNP Press. 